Short communication

\title{
Influence of cooling treatment on corrosion behaviour of steel EH40 in extremely cold seawater
}

Hengding Li, Yaohua Dong ",Yuanyuan Shen ${ }^{*}$, Xueting Chang, Dongsheng Wang, XiaofengLi, Yansheng Yin

Institute of Marine Materials Science and Engineering, College of Ocean Science and Engineering, Shanghai Maritime University, Shanghai, 201306, China

*E-mail: yhdong@shmtu.edu.cn, yyshen@shmtu.edu.cn

doi: $10.20964 / 2017.12 .51$

Received: 26 May 2017 / Accepted: 25 September 2017 / Published: 12 November 2017

The corrosion resistance of low-temperature steel EH40 with and without cooling treatment was investigated after salt spray testing under artificial conditions. The surface morphologies, chemical compositions, and corrosion rates of low-temperature steels EH40 were respectively analyzed by scanning electron microscopy (SEM), energy dispersive spectrometry (EDS), and mass loss method. Electrochemical impedance spectroscopy (EIS) measurements were employed to examine the effect of the cooling treatment on the corrosion mechanism of EH40. The results showed that pitting corrosion occurred for the steels subjected to cooling treatment at $-80^{\circ} \mathrm{C}$, which further accelerated their corrosion behaviors. By contrast, a uniform corrosion pattern was observed on the steel samples unsubjected to the cooling treatment. In the latter case, the formation of passive films on the steels surfaces lowered the rates for further corrosion.

Keywords: EH40 steel; Cooling treatment; Low-temperature seawater corrosion; Pitting

\section{$\underline{\text { FULL TEXT }}$}

(C) 2017 The Authors. Published by ESG (www.electrochemsci.org). This article is an open access article distributed under the terms and conditions of the Creative Commons Attribution license (http://creativecommons.org/licenses/by/4.0/). 